\title{
Analysis of loads on the shearing edge during Electrohydraulic Trimming of AHSS steel in comparison with conventional trimming
}

\author{
Zejun Tang ${ }^{\mathrm{a}, \mathrm{b}^{*}}$, Sergey F. Golovashchenko ${ }^{\mathrm{b}}$, John F. Bonnen ${ }^{\mathrm{b}}$, Alexander V. Mamutov ${ }^{\mathrm{c}}$, Alan J. Gillard ${ }^{\mathrm{b}}$, David \\ Bonnen $^{\mathrm{b}, \mathrm{d}}$ \\ a, * College of Mechanical and Electrical Engineering, Nanjing University of Aeronautics and Astronautics, \\ 210016, China. Corresponding Author, email: zjtang@nuaa.edu.cn \\ ${ }^{\mathrm{b}}$ Ford Research and Advanced Engineering, P.O. Box 2053, Dearborn, MI 48121-2053 USA \\ c Oakland University, Rochester, MI 48309 USA \\ ${ }^{\mathrm{d}}$ University of Michigan, 500 S. State Street, Ann Arbor, MI 48109 USA
}

\begin{abstract}
In order to achieve further weight reduction in automotive components, the technology of manufacturing of automotive panels from Advanced High Strength Steels is being developed. Electrohydraulic Trimming technology eliminates the necessity of accurate alignment of the shearing edges in trimming operation. Analysis of loads on the tool during high-rate EH trimming process has been performed. In order to investigate the effect of the process on the shearing edge performance, a dedicated finite element analysis procedure combining 3D shell and 2D solid models was developed. EH trimming experiments were carried out to validate the simulation model where elastic plastic deformation of the shearing edge was taken into account. The effects of the die geometry and number of trimming cycles on the tool contact loads and tool's plastic deformation were analyzed. This analysis was based on numerical simulation of deformation and fracture of the blank being trimmed in contact with the deformable shearing edge. Numerical analysis of the shearing edge deformation was performed in elasto-plastic formulation for the D2 tool steel inserts used in the experimental study and also in elastic formulation to define the maximum stresses which tool material needs to withstand to avoid its plastic deformation.
\end{abstract}

The results of the analytical study indicate that the maximum contact pressure is applied to the trimming tool at the lower endpoint of the shearing edge, but the point of maximum plastic deformation in the tool is found on the vertical wall of the shearing edge where it contacts the area of the blank where separation takes place. The shearing edge of the EH trimming die experiences less contact pressure and less plastic deformation with increase of the radius of the shearing edge. The shearing edge of the trim EH trim die has a tendency to dull after a number of trimming cycles. In addition, when compared with conventional trim die, the shearing edge of 
the EH trimming tool experiences slightly higher (10-15\%) contact loads than in conventional trimming.

However, plastic deformations occurring in the conventional trim die for shearing of identical material are larger. Analysis of loads on the EH trimming tool was repeated for purely elastic tool material to formulate the requirements to the material of the shearing edge.

Keywords: electrohydraulic trimming; shearing edge; finite element analysis; DP600 steel

\section{Introduction}

According to Cheah and Heywood (2011), one of the most common and effective methods for reducing fuel consumption and green house gas emissions by cars and trucks is weight reduction of the vehicle body. According to Davies (2003), replacement of mild steels with Advanced High Strength Steels (AHSS) is one of the more feasible options for achieving the necessary weight reduction. A variety of benefits has been found in product and design due to the use of AHSS and UHSS, but challenges and difficulties arise in manufacturing processes like trimming. Trimming is a necessary step to separate the excess sheet metal away from the final part. In conventional trimming processes described by Smith (1990), the blank is initially clamped to the lower shearing edge and then the upper trim steel moves down and trims extra metal from the panel. Difficult, frequent and costly tool alignments are required to maintain the small clearance consistent along the trimming line. Sufficient stiffness is needed in the trim die to resist opening the clearance between the shearing edges during operation. In addition, unbalanced forces in the trim die might cause the overlapping of the upper and lower trim tools which may lead to the failure of the shearing edge and result in poor trimmed surface quality and reduced trim die life. Presence of burrs on the trimmed surface often leads to difficulties in hemming and flanging operations for exterior and interior panels, like doors, hoods and decklids. The recommendations on sheared edge stretching provided by Smith (1990) indicate that the sheared edge stretching capability quickly diminishes with the increase of the burr height: for the burr height of $25 \%$ of the material thickness the sheared edge stretching is reducing almost factor of two. According to Chintamani and Sriram (2006), limited quality of sheared edge surface is one of the obstacles on the way of broader implementation of AHSS in automotive industry due to formation of burrs and splits from sheared surface.

Influence of speed on the shearing process and shearing surface formation was studied in a number of research papers. In early studies of high speed shearing processes, the general observation was that at high speed the shearing zone is more localized, the fracture profile is both clean and smooth, and shape distortions are 
minimized. According to the study by Johnson and Slater (1966) for sheet blanking, quality of sheared surface improved when cutting velocity was increased to $10 \mathrm{~m} / \mathrm{s}$. Nakagawa and Shimori (1974) confirmed significant improvement of sheared surface for crankshaft stamping when the speed was elevated to $10 \mathrm{~m} / \mathrm{s}$. Das and Sadollah (1979) observed similar results in bar cropping.

Breitling (1998) found experimentally that trimming with electromagnetic impact press developed by Netronics using high-velocity electromagnetic actuator results in a better quality fracture zone with a reduced burr compared to similar cutting conditions on a mechanical press. More detailed information on the existing electromagnetically driven high speed presses was provided by Taber et al. (2012). It should be indicated that due to the design of the press studied by Breitling (1998), the punch speed was limited to the velocity of $4 \mathrm{~m} / \mathrm{s}$. In contrast, the pulsed sheet metal forming technologies, such as explosive forming, electromagnetic forming or electrohydraulic forming can provide velocities of $100 \mathrm{~m} / \mathrm{s}$ and higher. The review of early experimental studies on explosive, electromagnetic and electrohydraulic forming and piercing processes was provided by Bruno (1968).

Mechanics of material fracture under impact velocity shear was studied by Klepaczko and Klosak (1999) where the importance of taking into account the effect of thermal softening and strain rate in addition to material workhardening was emphasized. According to Klepaczko and Klosak (1999), these factors result in critical impact velocity which is the result of strain localization in narrow area of the sample. The impact loading in this study was provided by high speed impact with the rigid tool. The geometry of the sample was modified to avoid the contact with the tool by fabricating the groove on the experimental samples. This technique provides an opportunity to study the material properties; however, makes the process of fracture substantially different from manufacturing processes where cutting is performed by the sharp edges rather than special technique of samples preparation.

A very detailed recent review of pulsed electromagnetic forming, joining and shearing processes was reported by Psyk et al. (2011). Electromagnetic forming and shearing processes have a significant limitation related to electric conductivity of workpieces and limited life of coils, which makes this process very attractive for aluminum alloys. Golovashchenko (1995) analyzed trimming of aluminum alloy tubes by using a compression coil and two internal mandrels with shearing edges. It can be seen from the finite element analysis work that fractures develop in two regions with increasing of the radial displacement of the tube. One originates on the external surface due to the meridian bending and tension, the other originates from the internal surface close to the edge of the mandrel. Kautz (2008) used an expansion coil to trim hollow profiles. The cutting 
process was investigated both with and without supporting die indicating that the process with the supporting die provides better quality of sheared surface. Uhlmann and Scholz (2003) studied electromagnetic shearing of sheets. According to their comparison with conventional quasi-static shearing, in electromagnetic cutting the buildup welding or loose burrs which often occur in conventional cutting of aluminum can be avoided. In addition, reduced production costs can be obtained through the one-side dies used in this process.

Prior accomplishments in explosive forming technology were reviewed by Mynors and Zhang (2002). Explosive forming processes can reach very high speeds of the blank and have no limitation on choice of the blank material. However, significant safety implications limit usage of explosive processes to very low volume production and defense applications. The current status of electrohydraulic forming technologies is described by Daehn (2006). This technology has an intermediate position between explosive and electromagnetic processes. Successful demonstrations of capabilities of electrohydraulic technologies to form tubular parts and pierce holes in them were discussed by Bruno (1968). The ideas of forming sheet metal parts and trimming them in one electrohydraulic tool was disclosed by Gafri and Livshitz (2004). However, shearing processes usually require substantially higher mechanical forces compared to forming operations; therefore, combining these processes in one tool leads to excessive energies of the process and overloading the die as well as the electrode system. The idea of electrohydraulic trimming using narrow small volume channel chamber was first formulated by Golovashchenko (2010). Initial analysis of the EH trimming process in the channel chamber was performed by Golovashchenko et al (2014). The principle of the recently developed EH trimming process is based upon the known phenomenon related to high voltage electrical discharge in a liquid. During a high voltage discharge of capacitors through a pair of electrodes submerged in a liquid-filled chamber, a high pressure and high temperature plasma channel is created between the tips of the electrodes. The shockwave in the liquid, initiated by the expansion of the plasma channel and flashing of water into steam, propagates toward the blank at high speed. The mass and momentum of the water in the shock wave accelerates the sheet metal blank into the trim die and then separates the blank when the deformations reach the fracture limit. In this case small volume of the chamber as well as close vicinity of the electrohydraulic discharge to the surface of the blank enables substantially higher efficiency of the trimming process which makes it appropriate for Advanced and Ultra High Strength Steels.

A one-side tool used in this process avoids the frequent and costly alignments compared to conventional trimming process. Moreover, an improved trimmed edge was found. However, pulsed trimming process usually causes high contact pressures in the trim tool. Outside of electrohydraulic applications, high strength materials 
like AHSS and UHSS also result in elevated loads in the trimming tools. Due to the novelty of the process, no literature was found examining the performance of a single-sided trimming die in EH trimming process. Therefore, the current paper aims to analyze the load and deformation characteristics found in the trim tool and effect of process parameters like die geometry and repeatable cuts on stresses and strains occurring in the EH trim die in order to define the appropriate shearing edge material prior to constructing the $\mathrm{EH}$ trim die.

\section{Experimental settings of electrohydraulic trimming process}

Figure 1 shows a cross-sectional schematic view of the tool setup. The channel chamber has a group of insulated electrodes which are connected to the pulse generator output. The insulation must be sufficient to prevent a short-circuit discharge to the chamber wall. The pulse generator ground can be connected to the chamber wall and serve as a simple ground electrode. First, the blank is clamped in between the chamber and the trimming tool to avoid material inflow from the flanges into the area between the trimming blade insert and the scrap guide insert. The cavity of the chamber is then filled with water. During a pulse, any entrained air found within a water channel is rapidly compressed and heated by the EH pressure pulse, consuming a significant amount of energy and decreasing the amount of energy reaching the sheet metal blank. Therefore, the water channels and all the geometrical features must be completely filled and all air must be evacuated from them. Once the EH trimming tool is completely filled with liquid, the high voltage is applied to the electrodes and generates the desired shockwave. When the blank starts to separate, any air that was trapped in the scrap cavity can move into the space opened up below the trimmed blank. So, there is no need for the scrap cavity to be under vacuum.

According to Singh (2003), in quasi-static hydro-piercing, pressure begins to drop rapidly as soon as separation of the blank and the slug begins. In order to avoid such a reduction in pressure, EH pressure pulse should have a rather short duration and high amplitude: a more intense pressure pulse results in faster acceleration of the blank, and in turn inertia causes the prevailing dynamic mode of deformation in the blank.

The trimming blade was fabricated from cold rolled, oil-hardened plate of D2 steel which was heat treated to HRC 62. The trim edge of the trimming insert should be as sharp as possible to avoid possible burrs, which might start occurring after a number of cuts. During the discharge process, the formed pressure wave accelerates the blank against the sharp trim edge and into the cavity between the trimming insert and the scrap guide insert, thus trimming the blank. 


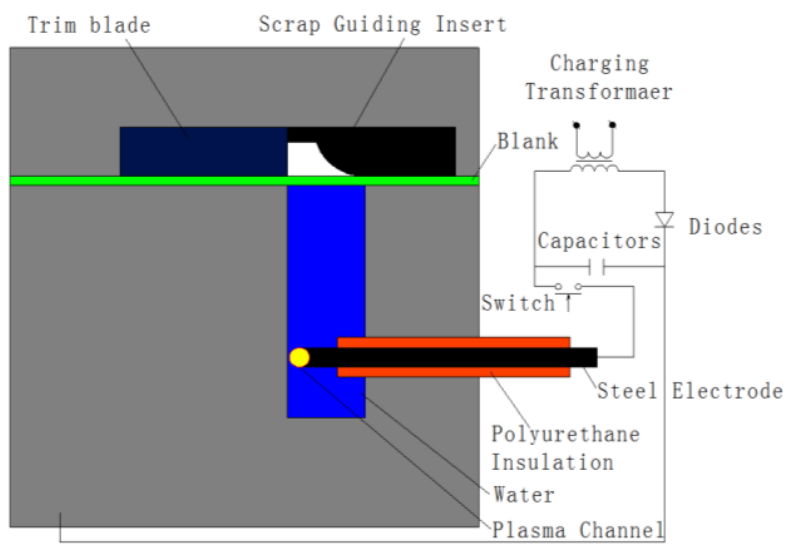

Fig. 1. Schematic view of the cross-section of EH trimming system.

The EH trimming experiments were carried out in the laboratory tool shown in Fig. 2. It consists of a narrow fluid channel machined into a rectangular steel block, $20 \mathrm{~mm}$ wide, $60 \mathrm{~mm}$ deep and $381 \mathrm{~mm}$ long. Three electrodes are evenly spaced across the length of the channel, in order to study the effect of the electrode position on the performance of the process. However, in the current study, just the middle electrode was used. The one-sided trimming die is positioned on top of the channel chamber. Three D2 trim blades hardened to 62 Rockwell C with the dimensions of $127 \mathrm{~mm} \times 50.72 \mathrm{~mm} \times 11.24 \mathrm{~mm}$ were mounted inside the trimming die. In this experiment, an existing 100kJ Pulse generator with maximum voltage of $25 \mathrm{kV}$, capacitance of $320 \mu \mathrm{F}$, resistance of $1.8 \times 10^{-3} \mathrm{Ohm}$, and internal inductance of $20 \mathrm{nH}$ was employed. This pulse generator has significant capability to produce the high energy plasma channel which expands extremely rapidly. The process provides rather high pulsed pressure due to rather small volume of liquid and close vicinity of the discharge to the surface of the blank. This generator is capable of EH trimming of full scale components which is subject of future research and development. In order to study the influence of the process on the trim tool, a number of DP590 blanks with $1 \mathrm{~mm}$ thickness were trimmed by charging the battery of capacitors to the voltage of $7.5 \mathrm{kV}$ which corresponds to $9 \mathrm{~kJ}$ of charging energy.

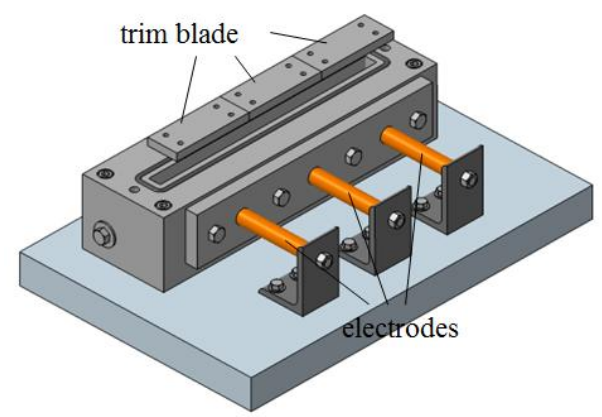

Fig. 2 EHT experimental tool 


\section{Simulation methodology}

The simulation of developed EH trimming process includes analysis of pulsed pressure propagation through the water filled chamber and high rate deformation followed by subsequent fracture of the sheet metal blank. In order to predict a local crack initiation of the blank and local loads on the sharp edge of the tool, it is necessary to use very fine mesh. Extremely high element density causes the computation time to become excessive when the blank and the water are included in a single model. Therefore, a hybrid simulation with a 3D shell element model and a 2D solid element model was employed in the present work. The water pressures applied to the blank are derived from the 3D simulation of the water filled chamber where the blank is represented by the shell element formulation, after which a 2D solid element model was used to simulate the blank deformation in contact with the deformable trimming die, crack propagation in the blank and the trimming tool analysis.

\subsection{A 3D shell element model}

The Arbitrary Lagrange Eulerian (ALE) method was used with a 3D shell element model, shown in Fig. 3, in LS-Dyna finite element code to simulate the EH pulse pressure formation process. Single point ALE multimaterial elements were used to model the water, plasma and vacuum. Specially, an elastic fluid material model was chosen for the water, while a linear polynomial equation of status with energy input was used to describe the material behavior of the plasma which results from the electrode discharge. A typical waveform of electric current propagating through the chamber is illustrated in Fig. 4a. The energy deposition rate is shown in Fig. 4b where deposited power is calculated for the whole initial volume of the discharge channel which was assumed to be $2 \mathrm{~mm}$ in diameter and 20mm long. A Belytschko-Tsay shell element formulation and fully integrated shell element formulation were used for the blank, the rigid die and binder, respectively. LS-Dyna keyword “CONSTRAINED_LAGRANG E_IN_SOLID” was used to define the contact between plasma, water and blank, while "FORMING_ONE_WAY_SURFACE_TO_SURFACE" formulation was used to describe the contact between Lagrange structures. The blank thickness was set at $1 \mathrm{~mm}$, while the major dimensions were shown in Fig. 3 and Fig. 5. After a successful evaluation of the 3D shell element simulation, water pressures were taken along the line running from position 1 to position 10 of the middle cross section as shown at right in Fig.3. 


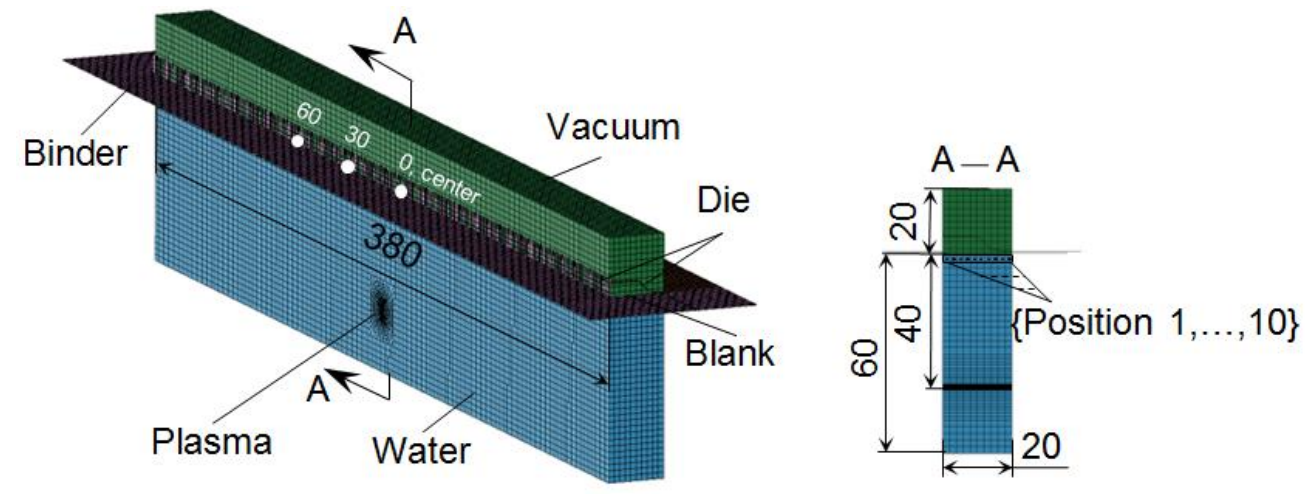

Fig. 3. EH trimming process 3D shell element model for pressure simulation (Unit: $\mathrm{mm}$ )
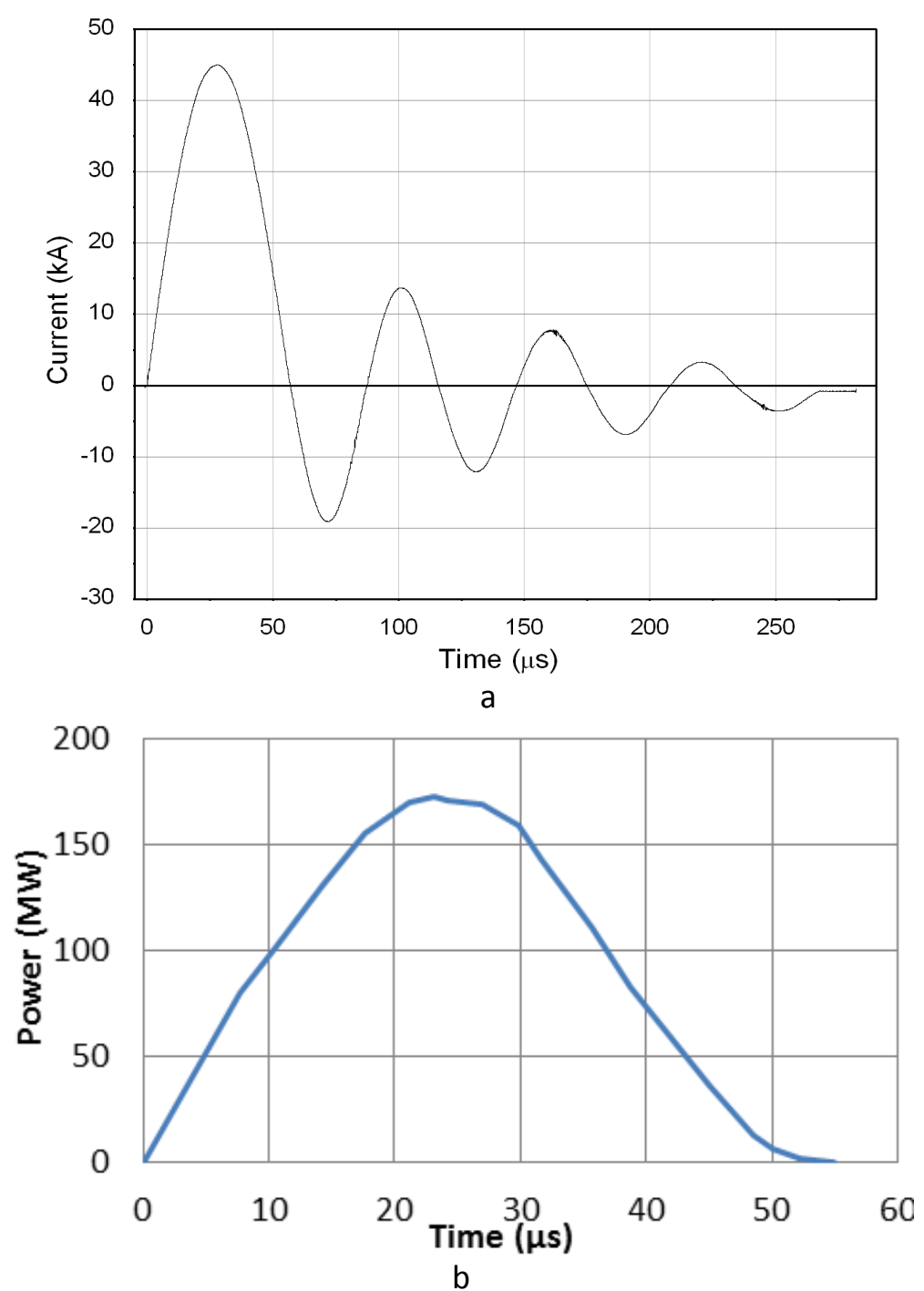

Fig. 4: a- waveform of electric current running through the chamber during EH trimming; $\mathrm{b}$ - energy deposition into the plasma channel during EH trimming process 
3.2 A 2D solid element model for trimming blank and tool deformation

The 2D solid element simulation model shown in Fig. 5 built using Abaqus explicit code was used to analyze the blank deformation, crack propagation in the blank and the tool life. The scrap guiding support and the binders were defined as discrete rigid elements. The blank was meshed with 4-node bilinear plane-strain quadrilateral elements with reduced integration (CPE4R). In order to analyze the loads on the shearing edge of the trim die, the trim blade was also meshed using CPE4R elements. Selection of the proper radius of the trim tool is the compromise between the amount of computational time and accuracy of the fracture process simulation. In order to simulate the local processes taking place on the shearing edge, at least several elements should be present on the sharp radius. According to prior engineering experience, the radius of the trim edge was set at $2 \%$ of the blank thickness. The mesh needs to be highly refined around the cut edge before the simulation to avoid mesh penetration issues. Due to the explicit nature of the integration procedure, decreasing the tool radius factor of two leads to increasing the number of elements factor of four and reducing the integration step of factor of two. As a result, the computational time is increasing factor of eight.

An ALE adaptive remeshing technique was adopted for the area of the blank close to the trim edge to avoid the large mesh distortions due to the large deformations of the material being trimmed. The scrap guiding support and the upper end of the trim blade were rigid. The initial height and length of the scrap guiding support were set at $2.5 \mathrm{~mm}$ and $10 \mathrm{~mm}$, respectively. The water pressures derived from the $3 \mathrm{D}$ shell element simulation were then applied on the water-side surface of the blank.

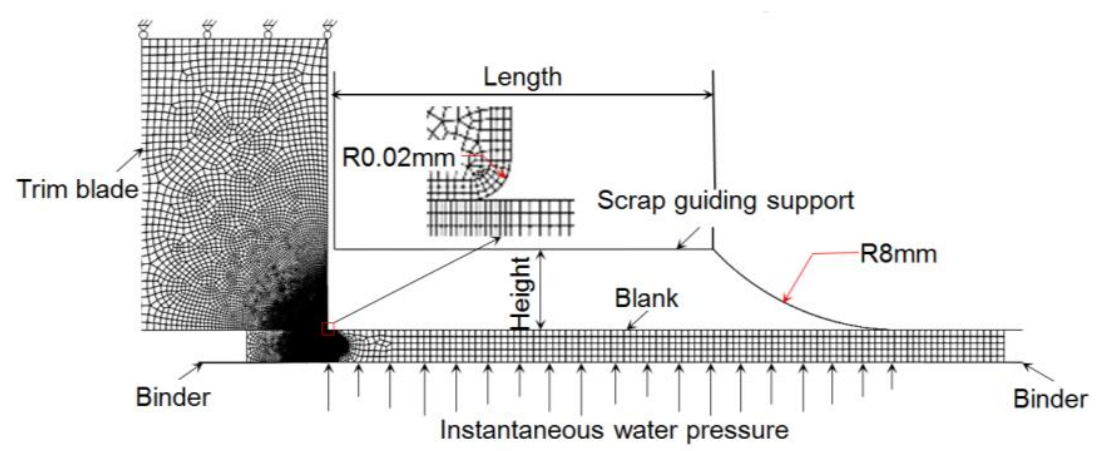

Fig. 5. 2D solid element model for EH trimming process 
In the whole 3D-to-2D simulation, DP600 steel blank with the thickness of $1 \mathrm{~mm}$ was chosen and the Johnson-Cook (1983) material model was used to describe the material's deformation behavior under high strain rate states seen in EH trimming process. In the 3D shell element simulation, a simplified Johnson-Cook (JC) hardening model without temperature effects was applied. A fixed failure strain (0.55) was used to judge the blank splitting. In the 2D solid element simulation, a JC hardening model (Eq. 1) with temperature influence was used. In equation (1), $\sigma$ is the effective stress, $\varepsilon$ is the effective plastic strain, $\dot{\varepsilon}$ is the strain rate, and $T^{*}$ is a form of homologous temperature. The parameters $A, B, n$ describe the work-hardening behavior, $C$ describes the strain-rate sensitivity, and $m$ describes the thermal softening. The fracture strain from the JC damage model (Eq. 2) was used to judge the initiation of the crack and crack propagation through the blank. In equation (2), $\eta$ is the stress-triaxiality factor defined as the ratio of the hydrostatic stress to the equivalent stress. Also, $d_{1}, d_{2}, d_{3}, d_{4}$ and $d_{5}$ are damage parameter constants. The evolution of JC damage parameter (D) shown in Eq. (3) is calculated based on the accumulated incremental effective plastic strains divided by the fracture strain. When the JC damage parameter D reaches 1.0, the element is removed from the analysis. JC flow stress parameters were used from the previous study by Thompson (2006), and JC damage model parameters were used from the study by Chen (2011). Parameters of both models for DP600 blank employed in the simulation are provided in Table 1.

$$
\begin{gathered}
\sigma=\left(A+B \varepsilon^{n}\right)(1+C \ln (\dot{\varepsilon}))\left(1-T^{* m}\right) \\
\varepsilon_{\text {failure }}=\left[d_{1}+d_{2} \exp \left(-d_{3} \eta\right)\right]\left[1+d_{4} \ln \left(\frac{\dot{\varepsilon}_{p}}{\dot{\varepsilon}_{0}}\right)\right]\left[1+d_{5} T^{*}\right] \\
D=\sum \frac{\Delta \bar{\varepsilon}_{p}}{\varepsilon_{\text {failure }}}
\end{gathered}
$$

Performance of trim blades was analyzed taking into account elastic plastic deformation of blades and considering D2 tool steel properties after heat treatment to $62 \mathrm{HRC}$ according to Becze (2002). The JC parameters and the stress strain relationship in term of shear stress and strain are provided in table 2 and Fig. 6 , respectively. The shear stress and strain derived from this model were converted into normal stress-strain flow curves. Obviously, the yield stress with the higher strain rates of $10^{4} \mathrm{~s}^{-1}, 10^{5} \mathrm{~s}^{-1}$ and $10^{6} \mathrm{~s}^{-1}$ is about $100 \mathrm{MPa}$ higher than that at the quasi-static state with the strain rate of $1 \mathrm{~s}^{-1}$, which is a positive factor for the tool life in 
EH trimming process. It should be indicated that with very limited amount of data available on behavior of tool steels at elevated strain rates, the parameters of the JC material behavior model were assumed to be valid throughout the whole range of strain rates observed in the electrohydraulic trimming process.

Table 1 Parameters of DP600 for Johnson-Cook hardening model and damage model

\begin{tabular}{lcccccc}
\hline Hardening & $A(\mathrm{MPa})$ & $B(\mathrm{MPa})$ & $n$ & $C$ & $m$ & $\dot{\varepsilon}_{0}\left(\mathrm{~s}^{-1}\right)$ \\
Model & 165 & 968.57 & 0.206 & 0.0145 & 0.868 & 1 \\
\hline Damage & $d_{1}$ & $d_{2}$ & $d_{3}$ & $d_{4}$ & $d_{5}$ & $\dot{\varepsilon}_{0}\left(\mathrm{~s}^{-1}\right)$ \\
Model & 0.7 & 0.3 & 5 & -0.006 & 0.0 & 0.02 \\
\hline
\end{tabular}

Table 2 Parameters of D2 for Johnson-Cook hardening model

\begin{tabular}{cccccc}
\hline$A(\mathrm{MPa})$ & $B(\mathrm{MPa})$ & $n$ & $C$ & $m$ & $\dot{\varepsilon}_{0}\left(\mathrm{~s}^{-1}\right)$ \\
1020 & 522.36 & 0.312 & 0.012 & 3.38 & 3500 \\
\hline
\end{tabular}

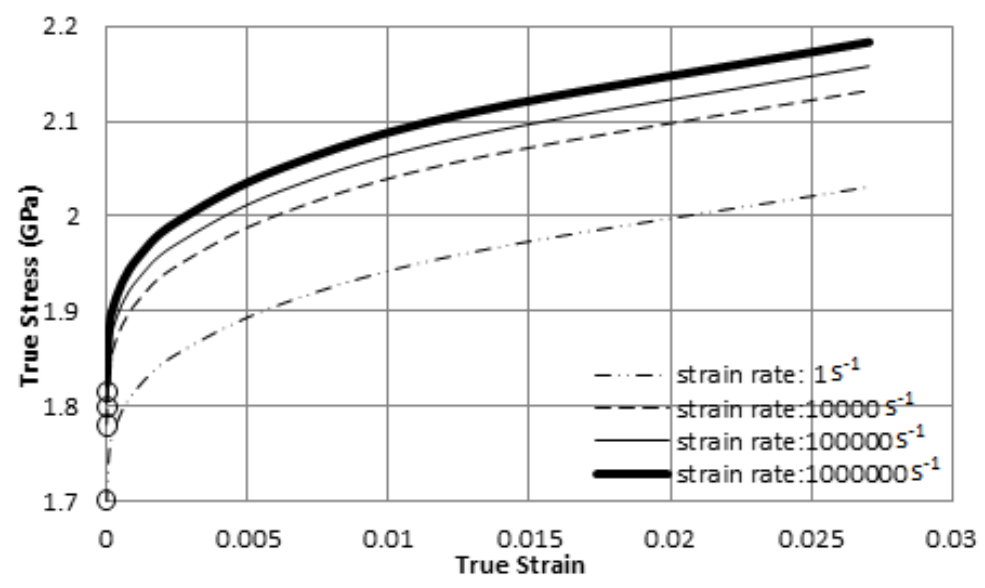

Fig. 6. Stress-strain curves of D2 steel shown at different strain rates

\section{Analysis of blank deformation in EH trimming and experimental verification of developed numerical model.}

Fig. 7 and Fig. 8 show the results of the 3D shell model numerical simulation in terms of pressure as a function of time at the selected points both lengthways and along the width direction. The pressure as applied to the blank is not a smooth curve due to the characteristic of the water pulse. The selected points all experience pressures with similar amplitude. The points far from the center have certain delay in pressure applied due to the wave nature of pressure propagation mechanism. Moreover, the simulation results indicate that the blank will completely separate within $25 \mu$ s. 


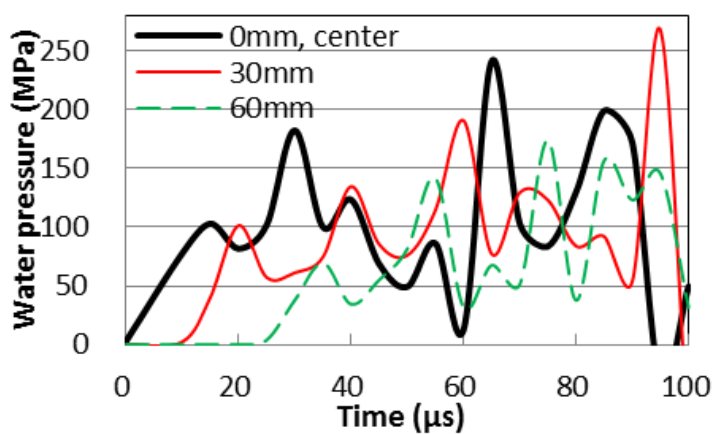

Fig. 7. Water pressure applied to the blank along the length of the chamber

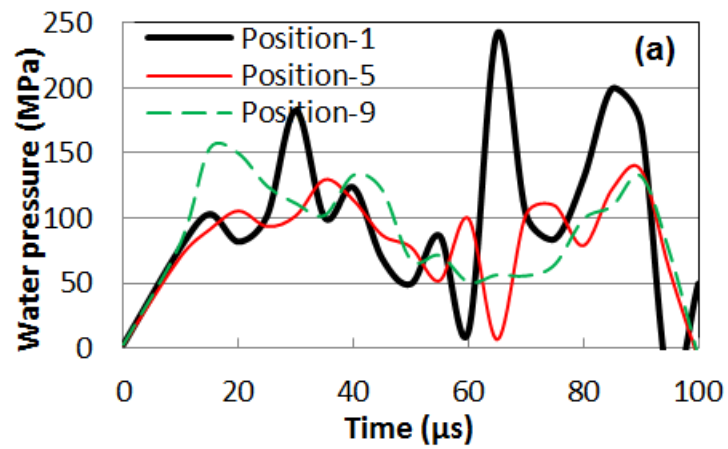

Fig. 8. Water pressure applied to the blank along the width of the chamber direction

To yield a better understanding of the blank deformation during the EH trimming process, the shape of the tool side surface of the blank at different times is shown in Fig. 9. The scrap section is bent into the trim die cavity driven by water pressure. In the right area, the blank is smoothly bent with small deformation along the generous radius of the supporting portion of the trim die. At the left, the blank material contacts the sharp radius trim blade at its edge. The material which stays in contact with the trim blade up to the shearing edge does not have any significant flow due to friction. The unsupported material deforms and flows forced by the water pressure along the vertical side of the trim blade. This material flow results in substantial stretching deformation. This mechanism of fracture is different from the mechanism of fracture in conventional trimming: the crack in EH trimming originates from the sharp edge of the tool side and propagates to the water side while in conventional trimming the mechanism of fracture really depends on the clearance between the shearing edges and may involve both moving and stationary shearing edges or only one of them. At the beginning of the blank deformation, the trim blade is mainly subject to vertical contact pressures. Later the unsupported material is pulled into the trim die cavity, and the trim blade is then subject to both vertical contact and non-vertical contact loads. The JC damage initiation criterion (JCCRT) distribution in the blank during EH trimming is illustrated in Fig.10. At $20.0 \mu \mathrm{s}$, the blank deformation is rather limited: the maximum JCCRT is 0.3 . At $22.0 \mu \mathrm{s}$, the blank 
material is forced further into the trim die cavity, but the maximum JCCRT is still 0.34. The main deformation zone begins to move to the shearing edge side. After that, the deformation will concentrate mostly near the shearing edge and keep on increasing. At $24.0 \mu \mathrm{s}$, the maximum JCCRT reaches 1.0. The accumulated deformation reaches the critical limit and fracture starts to propagate from the sheared edge area of the blank.

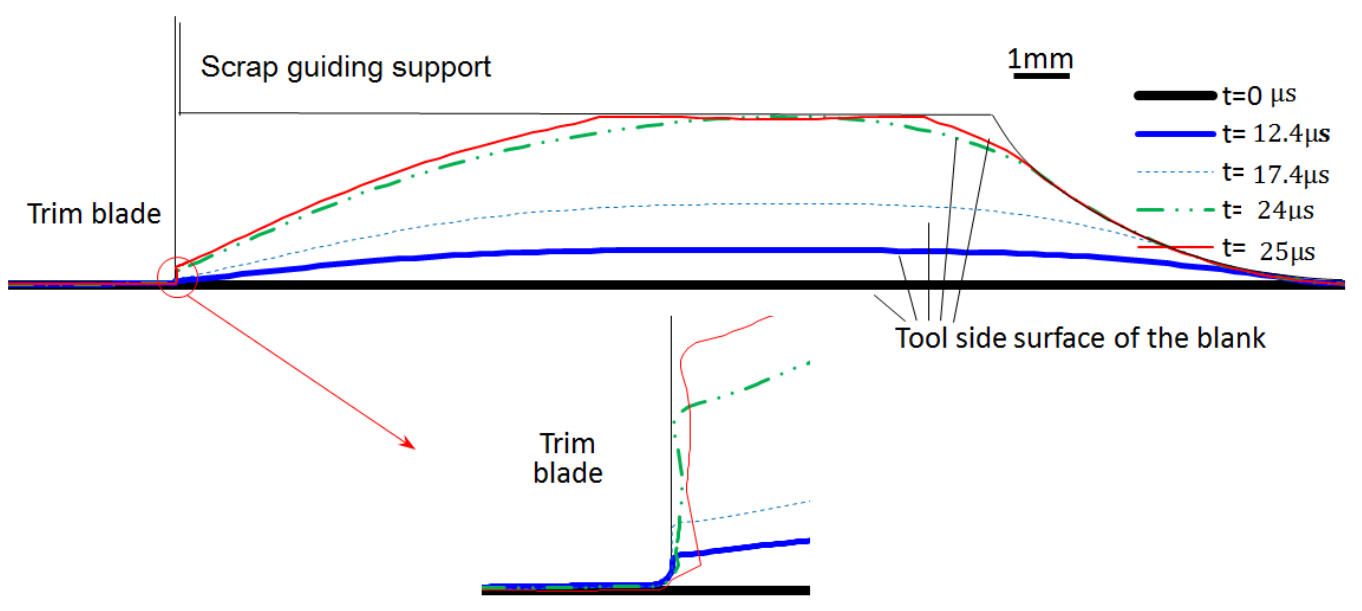

Fig. 9. Shape of the blank cross section during EH trimming

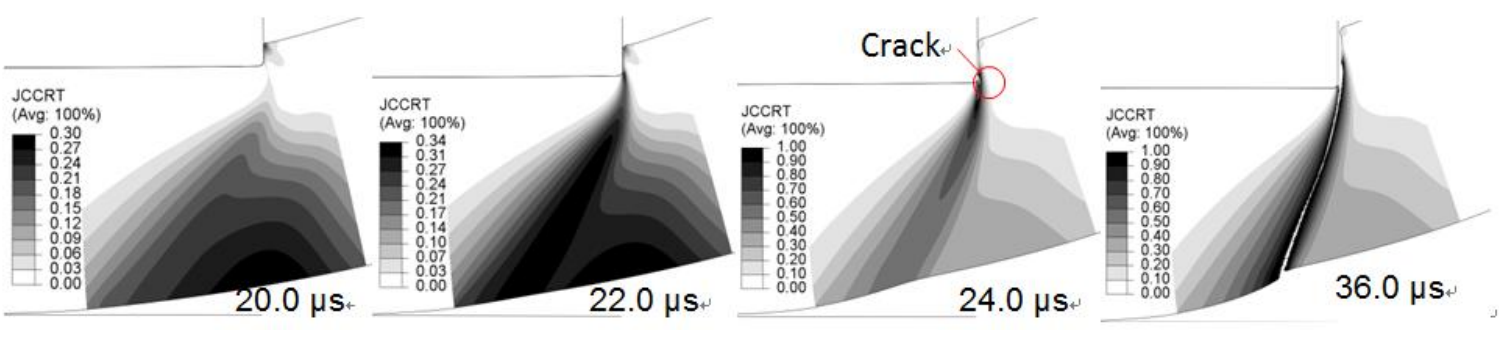

Fig. 10. Johnson-Cook Damage Criterion distribution of the blank cross section during EH trimming

Experiments were carried out by using the laboratory tool illustrated in Fig.2. An example of a trimmed sample is shown in Fig. 11. The process parameters were selected after few trials the results of which varied slightly by the length of the trimming line. In order to minimize the load on the chamber and the trimming blades, the minimal energy level at which the trimming process was taking place along the whole trimming line was selected. Lowering the energy below this limit resulted in partial separation starting from the area adjacent to the electrodes. Further increasing the energy also provided successful separation of part and scrap along the trim line, but leads to overloading of the discharge chamber, faster erosion of the electrodes and earlier fracture of the electrode insulation. Specific amount of energy required for separation of the scrap along required length of trimming line depends upon many factors such as inductance, resistance and capacitance of the discharge circuit, thickness, density and strength of material being trimmed, and sharpness of the cutting edges. Therefore, 
this amount of energy varies from one pulse generator to another as well as may vary even for different interface designs between the pulse generator and the electrohydraulic chamber. During this study, there was no attempt to optimize the process and the discharge parameters which would require variation of pulse generator capacitance. Since this is the first attempt to understand the behavior of the tool in the EH trimming process, minimum required energy was considered to be an acceptable criterion for the initial validation of the developed numerical models.

Cross-sections of samples were obtained at two positions 1-1 and 2-2, respectively. Cross-section at position 1-1 can indicate the crack initiation, while the cross-section at position 2-2 can define the full trimmed parts' shape. The samples were grinded and polished. Fig. 12 illustrates the observed cross-sections for crack initiation and full split. The experimental results confirm the fracture mechanism of the blank observed in numerical simulation. It can be seen from both simulation and experimental results that the crack initiates from the tool side instead of the water side or both sides. The burr height observed in EH trimming is rather small and is similar to the radius of the shearing edge of the $\mathrm{EH}$ trimming tool. In conventional trimming, the steady shearing edge often has small influence on the material fracture mechanism, and the burr height might be substantially larger and reach $10-40 \%$ of the material thickness, as it was reported by Chintamani and Sriram (2006) for AHSS and by Li (2000) for aluminum alloys.

In order to verify the simulation model in addition, a comparison was made in Fig. 12(c) between the geometries of experimentally and simulated as-trimmed parts. The shape and size of the simulated part maintains good fidelity to that of the experiment.

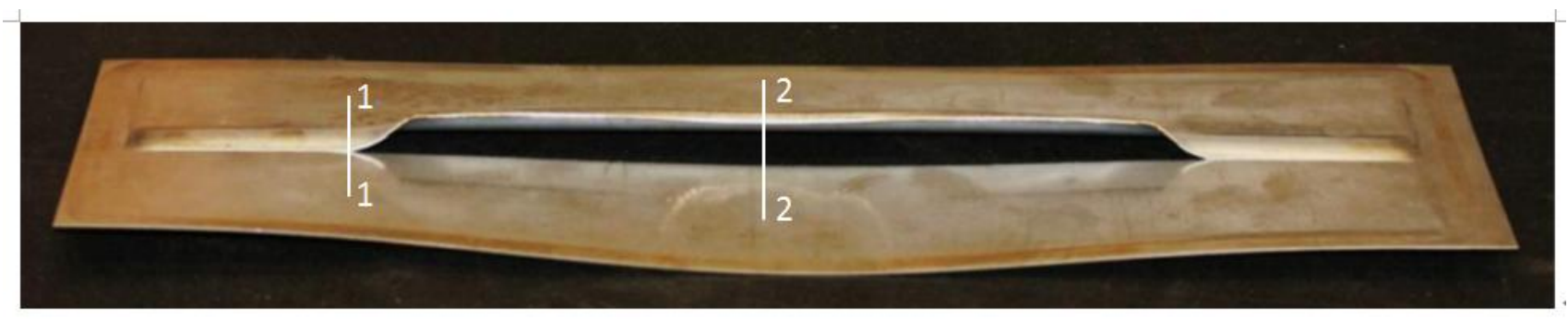

Fig. 11. Sample of DP600 sheet after EH trimming 


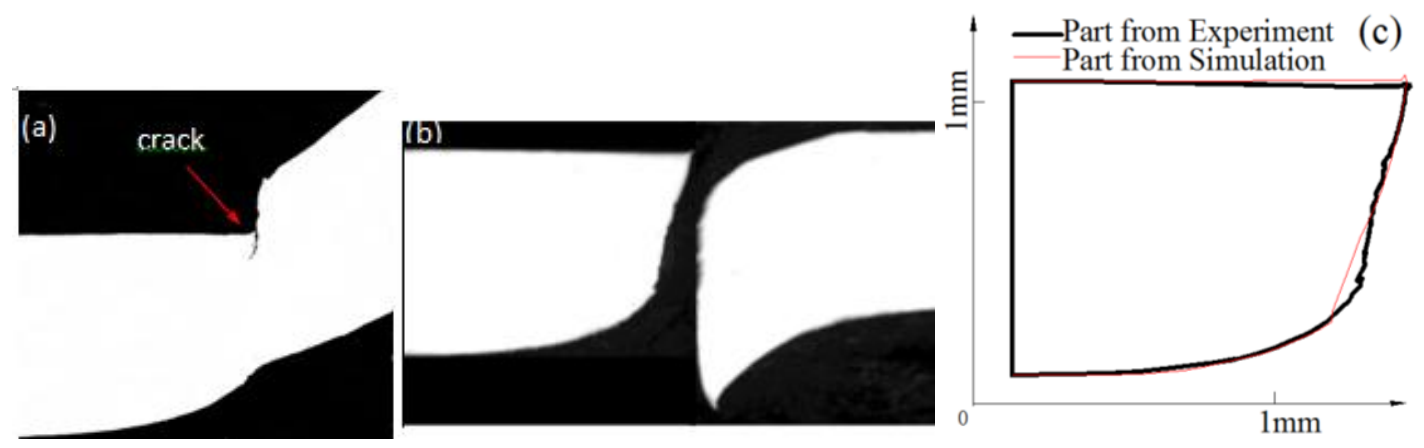

Fig. 12. Cross-sections of EH trimming parts (a) with crack initiation (b) with full trimmed crack (c) comparison between simulation and experimental result

\section{Results and Discussion}

5.1 Influence of blank strain rate and plastic work on die analysis

Electro-hydraulic trimming is a high speed process resulting in large deformations in the sheet metal blank adjacent to the sharp shearing edge. As a result of work hardening and strain rate phenomena, the flow stress in the blank increases which can change the contact loads and thus analysis is required. Fig. 13 (a) and Fig. 13 (b) show the distribution of maximum principal strain rate for strain rates above $10^{5} \mathrm{~s}^{-1}$ at time steps of $20 \mu \mathrm{s}$ and 23.6 $\mu$ s, just before the blank splits. Assuming the Johnson-Cook model is valid, it indicates that the strain rate in the zone closest to the trim edge exceeds $10^{6} \mathrm{~s}^{-1}$ and creates a flow stress increase in the sheet of between 200 to 300MPa greater than that found at a strain rate of $1 \mathrm{~s}^{-1}$. Under adiabatic conditions this intense plastic work within the deformation zone causes a local temperature rise which, in turn, causes local material softening. Fig. 13 (c) and Fig. 13 (d) show the temperature distribution field for temperatures exceeding $50^{\circ} \mathrm{C}$ at the $20 \mu$ s and 23.6 $\mu$ s time steps. The temperature in the zone closest to the shearing edge reaches a peak of $500^{\circ} \mathrm{C}$, implying a material strength reduction in the neighborhood of 400 to $600 \mathrm{MPa}$ based on the JC hardening model. This reduction in blank strength also significantly lowers the contact pressure. As a result both strain rate and temperature effects must be included in EH trimming simulations to more accurately estimate trim die stresses. These factors are estimated assuming adiabatic conditions and a rate dependent material model for the blank. Fig. 14 shows a comparison of maximum die contact pressure both with and without temperature influence. Including temperature effects in the simulation reduces the contact stresses by approximately $200 \mathrm{MPa}$. 

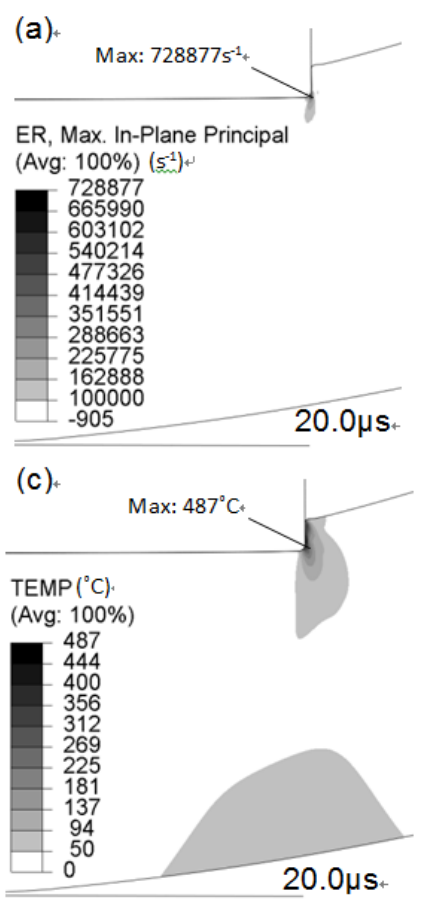
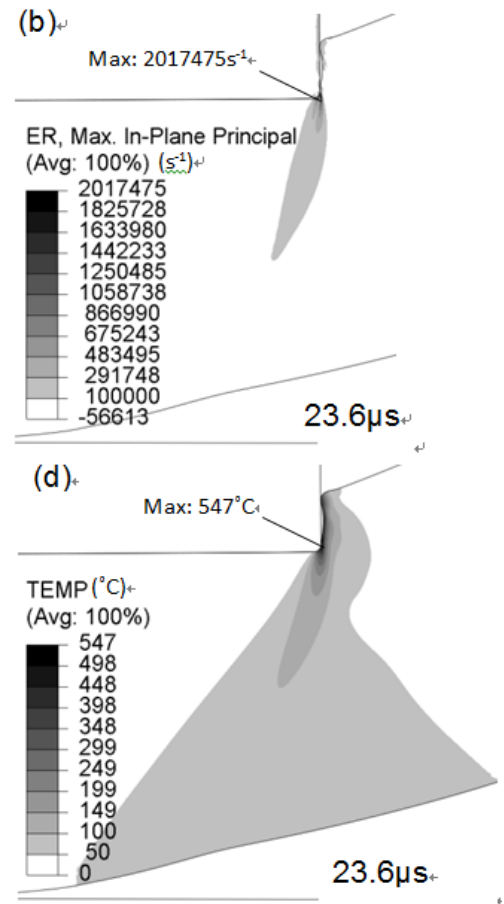

Fig. 13 Distribution of strain rates and temperatures within the blank

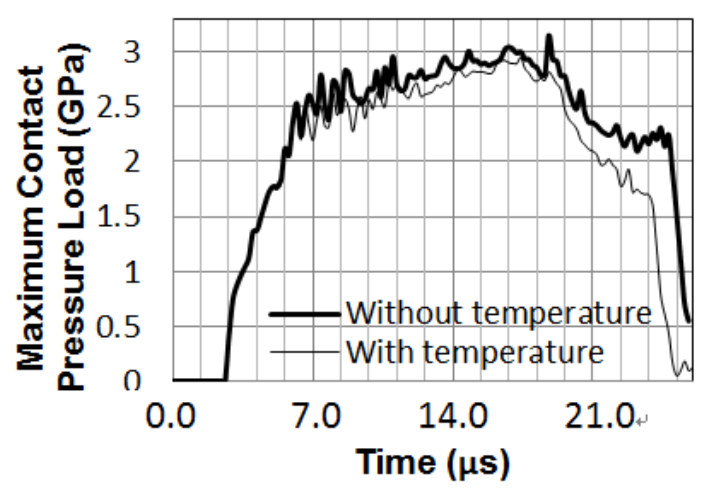

Fig. 14 Maximum contact pressure on the trim blade

5.2 Characteristics of the contact pressure and the die deformation

Adiabatic conditions were assumed in the simulation of the resulting contact pressures and deformation in the trim blade. Fig. 15 shows the distribution of contact pressures resulting in the trim edge. As shown in the figure, Point A and point $B$ represent the fillet endpoints while point $\mathrm{C}$ lies above point $\mathrm{B}$ on the side wall. The tool radius as illustrated in Fig. 15 is shown at high magnification to demonstrate the locations of points A, B, and $\mathrm{C}$ - for reference the trim edge radius used in numerical simulations was $0.02 \mathrm{~mm}$. The horizontal axis 
represents the distance along the trim blade surface with its original at point A. The horizontal surface ending at point A remains in contact with the blank throughout the entire $\mathrm{EH}$ trimming process.

As can be seen in Fig. 15, the contact pressures are mostly concentrated at the fillet and surrounding area. Once the scrap begins to separate from the part (after $24.6 \mu \mathrm{s}$ ), contact pressures remain below $700 \mathrm{MPa}$ and are concentrated to the left of point A. Therefore, the part of the trim cycle before crack initiation does the greatest damage to the trim edge. Before crack initiation, the contact pressure curves show two groups of peak values. The highest peak is found at point $\mathrm{A}$, where the fillet meets the horizontal surface. The maximum contact pressure reaches nearly $3 \mathrm{GPa}$ at $17.4 \mu \mathrm{s}$. At this moment, the other peaks average less than $1.8 \mathrm{GPa}$ and are located in area $\mathrm{C}$ (not indicated on graph) at the point where the upper edge of the scrap contacts the die during trimming. During crack initiation Point A sees $1.7 \mathrm{GPa}$. If the contact area is defined as the area of the die surface where pressures exceed $1 \mathrm{GPa}$, then it is about $0.2 \mathrm{~mm}$ wide and centered around point A.

The maximum contact pressures seen across the entire trim blade surface during the EH trimming process is shown in Fig. 14. The maximum contact pressure increases more or less constantly from $2.5 \mathrm{GPa}$ to about 3GPa during the time period from about $6 \mu$ s up to the $17.4 \mu$ s mark. During this period only a small amount of the upper area of the scrap contacts the trim blade side wall around area $\mathrm{C}$ during the trimming process. After 17.4 $\mu$ s simulation results indicate that the trim blade is subjected to monotonically increasing side wall contact pressure from the blank. In the period between $17.4 \mu \mathrm{s}$ and $23.6 \mu \mathrm{s}$, the maximum contact pressure decreases quickly. Subsequently, the overall maximum contact pressure decreases over a short $14 \mu$ s period, during which the crack completely propagates through the blank. At the end, the contact pressure suddenly decreases to zero once the blank fractures. In summary, the trim edge is subjected to maximum contact pressures over the $0.2 \mathrm{~mm}$ wide patch centered about the beginning of the radius on the horizontal surface and occurring before crack initiation in the blank.
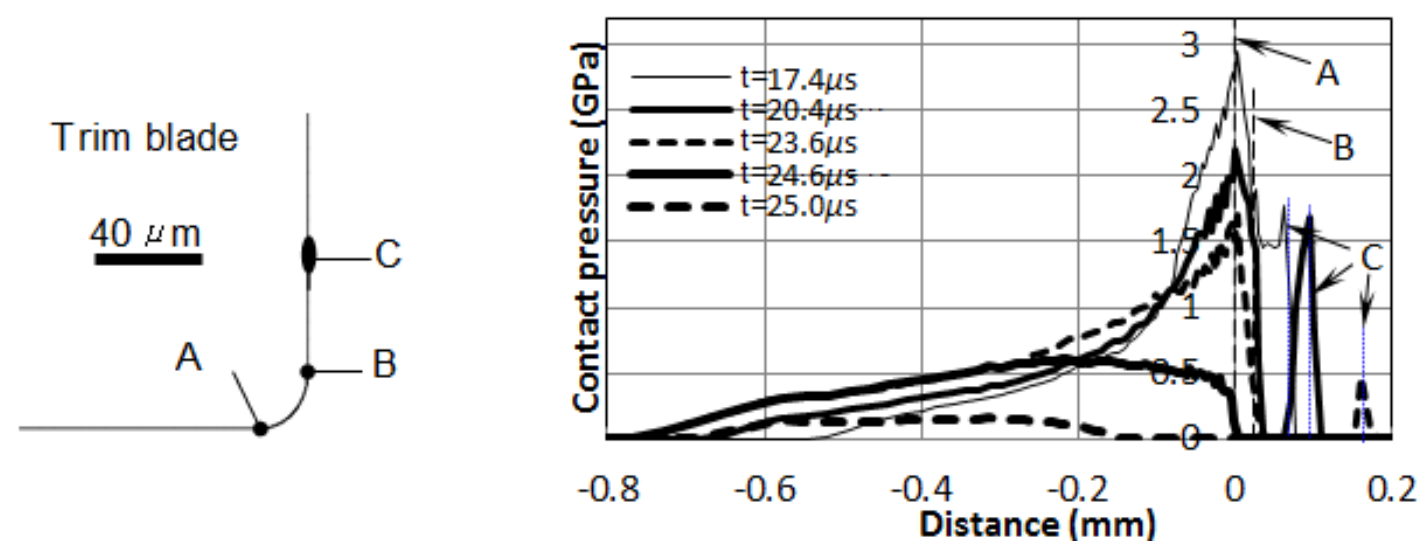

Fig. 15 Contact pressure distribution on the trim blade surface at different times 
In order to find the most heavily loaded area for the tool, both the stress state and plastic deformation have been analyzed. Fig. 16 shows the results from a numerical simulation of the stress states at points A, B and C at $10 \mu \mathrm{s}, 12.4 \mu \mathrm{s}, 15 \mu \mathrm{s}$ and $18.6 \mu \mathrm{s}$. It should be noted that the material of the blank is in contact with the entire area of the trim die from Point A through Area C for the entire timeframe illustrated in Fig.16; therefore, this area of the tool is subject to substantial compressive loads. Just as in Figs 15a, in Fig. 16, the $\mathrm{x}$ and $\mathrm{y}$ axes are represented the horizontal and vertical directions, respectively, and in this case the $\mathrm{z}$ axis is perpendicular to the paper. The principal stress directions change over time due to time varying combinations of contact pressure and friction at each selected point of interest at the surface. Observing the stresses at point A, the material is subjected to a fairly constant level of hydrostatic compression throughout the process. Although the maximum contact pressure is observed at point A, the von-Mises equivalent stress at this point holds essentially constant at around $1 \mathrm{GPa}$, and, thus, the material at point A remains predominantly elastic.

At point $\mathrm{B}$, the material is initially subjected to tensile stress in the horizontal direction and compressive stresses at the other two directions at $10 \mu \mathrm{s}$, and subsequently it is subjected to three essentially constant compressive stresses in each of the remaining time slices. The maximum equivalent von-Mises stress at point B does not exceed 1.3GPa.

Before $18.6 \mu \mathrm{s}$, the stresses at point $\mathrm{C}$ in the horizontal direction can be neglected compared with other principal stresses. The material at Point $C$ is essentially in a state of combined plane stress and plane strain - the latter from modeling - and results in a high equivalent stress that drives plasticity in that location. During the timeframe between $16 \mu$ s and $18.6 \mu \mathrm{s}$, the equivalent stress at $\mathrm{C}$ increases to $1.8 \mathrm{GPa}$.
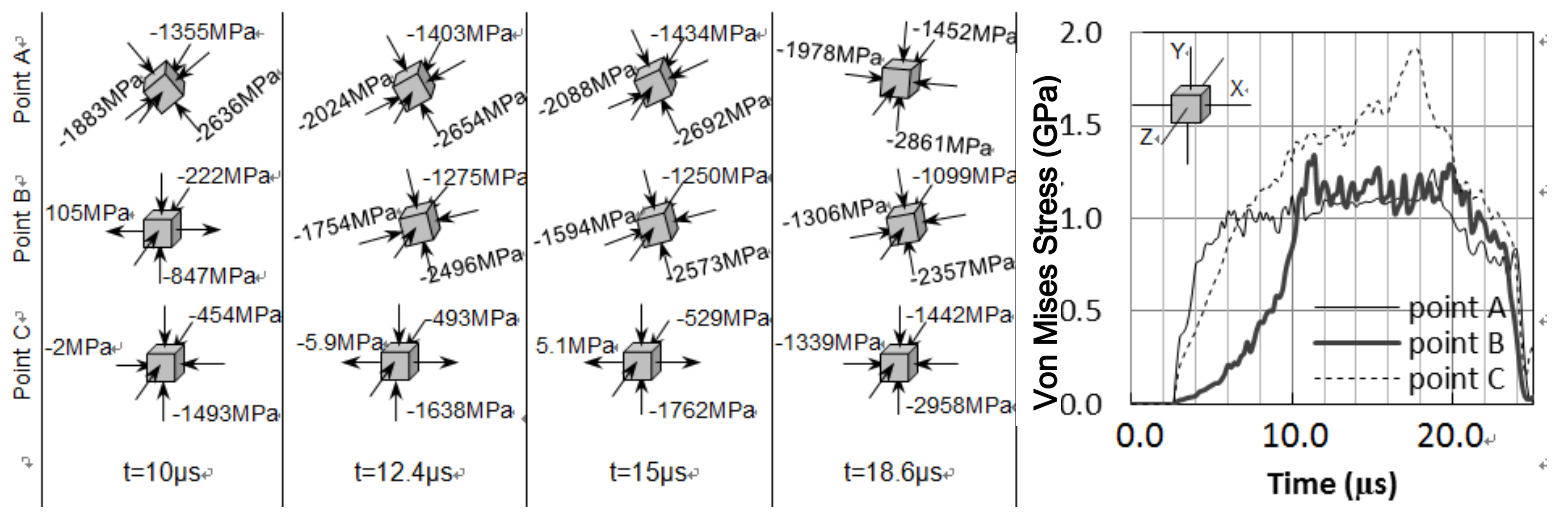

Fig. 16 Stress state along the trim blade surface at different times

Fig.17 illustrates the distribution of the plastic equivalent strains in the trim blade. In order to estimate the plastic deformation in this region more accurately, the equivalent plastic strain rate distribution in the trim edge 
was obtained from the simulation and is shown in Fig. 18. The strain rate in the trim edge is mostly in the range of $10^{4} \mathrm{~s}^{-1}$ to $10^{6} \mathrm{~s}^{-1}$. According to the strain rate dependent stress-strain curves found in Fig. 6 , the trim edge will have a flow stress between 1.78GPa to $1.82 \mathrm{GPa}$. Again, material around point $\mathrm{C}$ experiences plastic deformation while material around points A and B are loaded elastically. It can be seen that the plastic deformation region is mostly concentrated in the area above the shearing edge, and the region of maximum deformation is on the trim blade side wall just under the surface at point $\mathrm{C}$ and reaches a maximum at $18.6 \mu \mathrm{s}$. Subsequently, the plastic deformation zone expands without intensification until 23.6 $\mu$ s mark.

In summary, the maximum contact pressure is located at the lower endpoint of the trim edge, while the maximum plastic deformation is found just under the surface of the vertical sidewall just above the trim edge radius.

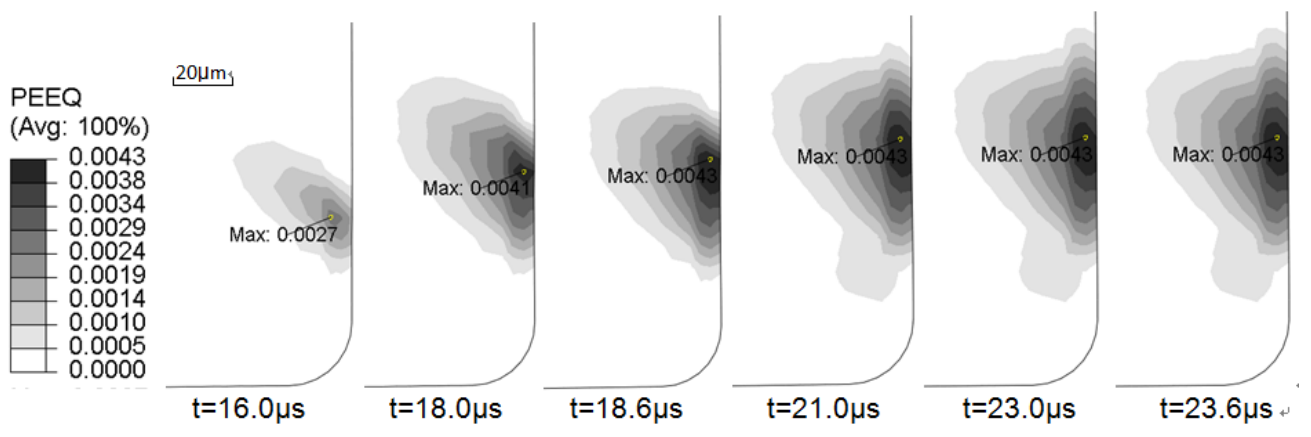

Fig. 17 Plastic equivalent strain distribution in the trim blade at different times

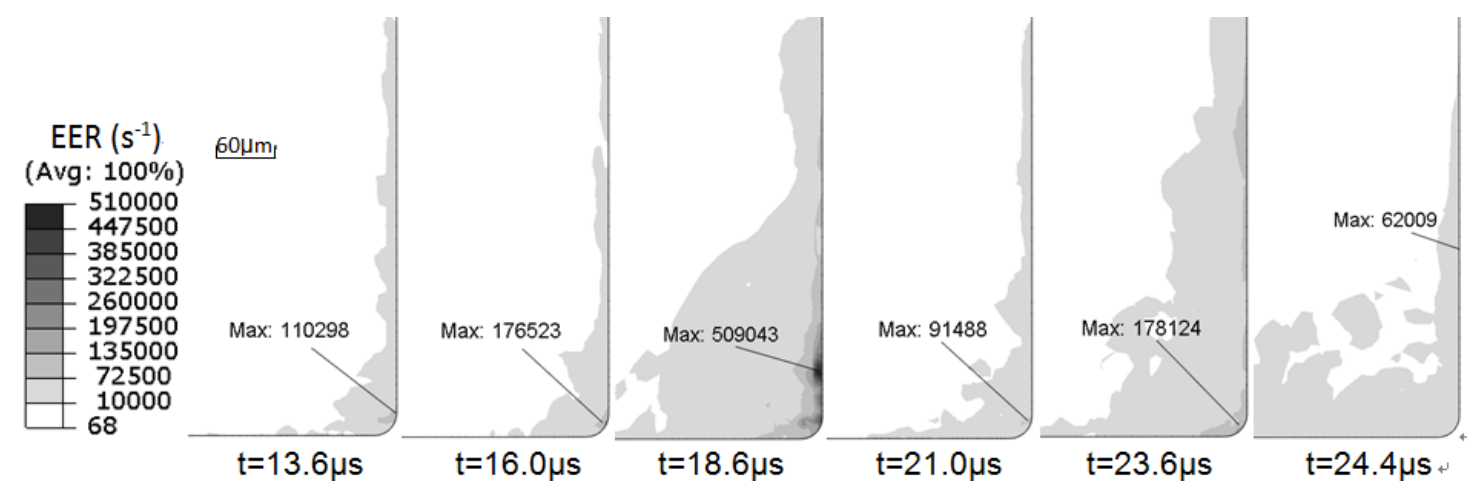

Fig. 18 Equivalent strain rate distribution in the trim blade at different times

5.3 Influence of die geometry on die loads and deformation

An overall schematic of the single sided trimming process, including shearing edge radius, supporting die height and length, is illustrated in Fig. 5. A parametric study was performed in order to identify the effect of EH 
trim tool design parameters on maximum shearing edge deformation. The shearing edge radius, often associated with tool sharpness, is the single-most critical parameter. Fig. 19 (a) and (b) show the influence of the trim blade radius on resulting contact pressures and plastic deformations within the trim blade. The maximum contact force is concentrated around the trim blade cutting edge. Sharper radii result in a smaller local contact area. As a result, the sharper trim blades are exposed to marginally higher contact pressures, as shown in Fig. 19(a). Further, there is more plastic deformation in trim blades with sharper cutting edge. Based on these considerations, it is less damaging for a trim blade to have a larger shearing edge radius, assuming that the resulting trimmed blank quality is satisfactory.

Fig. 19 (c) and (d) demonstrate the diminishingly small influence of supporting die height on contact pressure and plastic deformation within the trim blade. In order to demonstrate this point further, a comparison of the deformed blank profile is illustrated in Fig. 20 (a) as a function of supporting height. Since all the profiles are coincident, the figure clearly demonstrates that, at the moment of peak maximum contact pressure, the profiles show no influence of supporting die height. Therefore, the maximum contact pressure and the plastic deformation within the trim blade are not particularly sensitive to the selected supporting die heights.

Fig. 19 (e) and (f) show the influence of the supporting die length on the contact pressure and plastic deformation found within the trim blade. Clearly, up to $23 \mu \mathrm{s}$, the maximum contact pressure is almost insensitive to supporting die length. However, the trim blade with a shorter supporting die length exhibits larger plastic deformation. Fig. 20(b) shows the corresponding water side blank surface profile at the moment of the peak maximum contact pressure. Obvious differences are observed at the right hand side of Fig. 20(b), arising from the different supporting die lengths. Conversely, at the left hand side of Fig. 20(b), more material was pulled up alongside the trim blade side wall by the use of a shorter supporting die length. More friction and larger contact areas result in more plastic deformation within in the trim blade. Therefore, longer supporting die lengths are better for the tool design. 

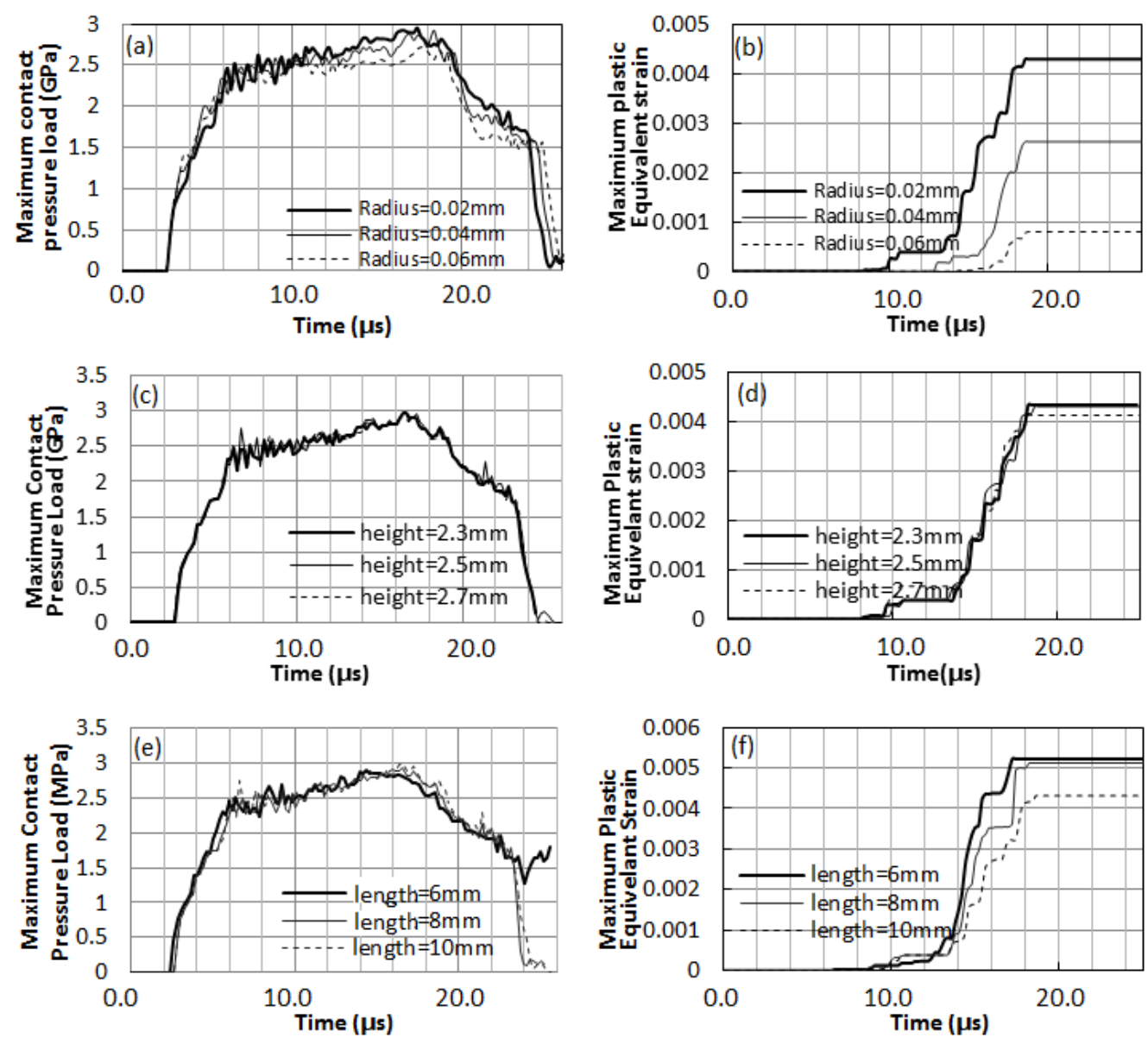

Fig. 19 Influence of tool geometry on contact pressures and maximum plastic deformation: (a) and (b) effect of cutting edge radius; (c) and (d) effect of supporting die height; (e) and (f) effect of supporting die length
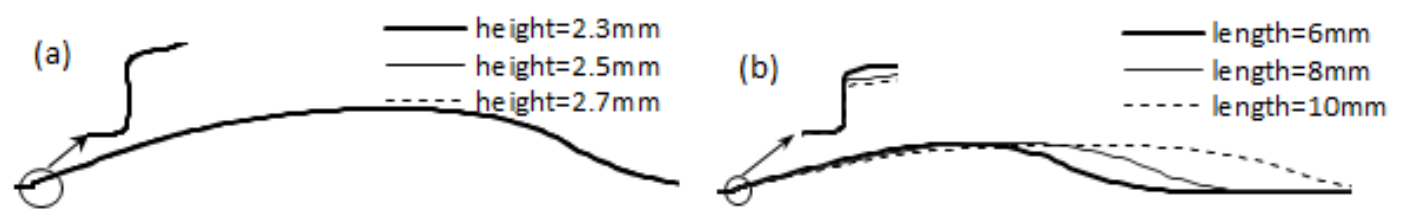

Fig. 20 Water side blank surface profile at peak maximum contact pressure: (a) different supporting die heights ( $2.7 \mathrm{~mm}$ and $2.5 \mathrm{~mm}$ overlay the $2.3 \mathrm{~mm}$ profile); (b) different supporting die lengths

5.4 Effect of the number of trimming cycles on deformation within the trimming die

In order to study the effect of the number of trimming cycles on trim die deformation and damage, the distribution of the plastic strain components was analyzed using a trim blade cross section, and the results are shown in Fig. 21. As discussed before, plastic deformation is concentrated in the side wall around the area just 
above the cutting edge of the trim blade. Fig. 21(a) shows tensile plastic deformation in the horizontal plane near the surface just above the cutting edge. At the same time, there is compressive plastic deformation, as seen in Fig. 21(b) along the vertical direction, in the same volume above the cutting edge. Therefore, the radius of the cutting edge tends to become larger. It corresponds with the general trend of shearing edge evolution of the conventional blanking die studied by Maeda and Matsuno (1967).
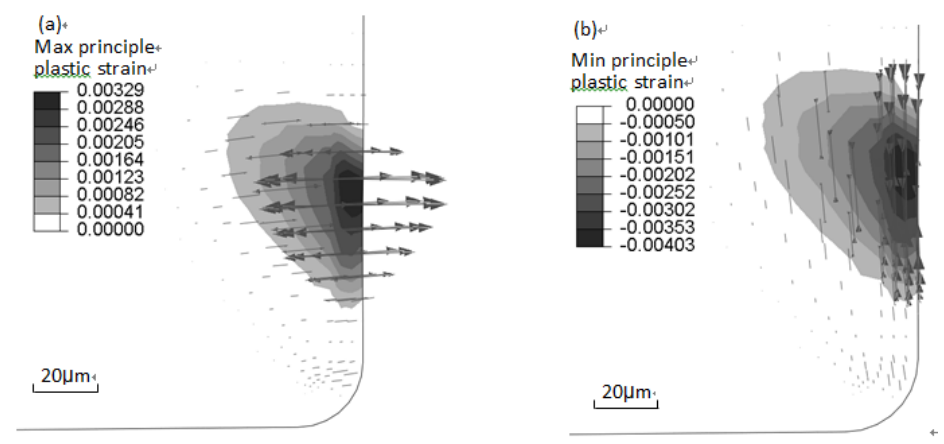

Fig. 21 In-plane principal plastic strain components distribution at 18.6 $\mu$ s: (a) Maximum principal plastic strain (b) Minimum principal plastic strain

In order to understand the evolution of the shearing edge deformation, an experimental study was performed to identify the shape changes in as-received condition shearing edges after 10 cuts and 30 cuts. It should be emphasized that identifying the dynamic properties of either the tool material or the AHSS sheet material as a function of strain, strain rate and temperature in wide range of parameters is beyond the scope of this study. Hence, existing experimental data was employed to estimate the level of plastic deformation in the tool and to determine general trends in how tooling design might change die loads as well as fracture/failure mechanisms. From the existing stamping practice identified by Smith (1990), shearing tools should be fabricated with a sharp edge, and, during the life of the tool, re-sharpening of the shearing edges should periodically take place. Therefore, the experimental trim blades employed in this study were fabricated with as sharp an edge possible within capabilities of the experimental fabrication facility employed for this effort. The actual radius of the cutting edge was identified after the sharpened tool was fabricated by sectioning and measuring tool sharpness under the microscope from the resulting cross-section: the shape of the newly fabricated shearing edge can be approximated with a $6 \mu \mathrm{m}$ radius arc. This radius is smaller than the computationally marginal $20 \mu \mathrm{m}$ radius used elsewhere in this work. Some visible roughness was observed on the experimental trimming blade surface even though the blade was ground - this roughness may be reflected in the experimental results. Based on these considerations, the results of numerical simulation should be treated as 
a qualitative trend which helps to the tooling designers estimate the anticipated stresses in the tool and make the proper choice of die material and surface treatment.

In the experimental study presented below, trim blades were fabricated from D2 material and heat treated to a hardness of HRC62. The EH trimming experiments were performed using the tool shown in Fig.2 in a fashion similar to the trimming experiments discussed above. Three separate but identical trim blades were used in this study. One trim blade each was cross-sectioned in following conditions: as-received condition, after 10 $\mathrm{EH}$ trimming cycles and after $30 \mathrm{EH}$ trimming cycles. Since the initial experimental shearing edge radius does not correlate accurately with the shape of the shearing edges used in numerical simulation, no quantitative comparison of analytical and experimental results are made - the purpose of the experiment was to confirm the general tool deformation trends predicted by the numerical model.

The micrographs of the sheared edge cross-sections are provided in Fig. 22. In general they confirm that some plastic deformation is occurring above the initial radius of the shearing edge. These results also confirmed that heat treated to HRC 62 tool steel D2 does not provide sufficient strength to withstand the applied cutting loads without plastic deformation: the shape of the cross-section of the shearing edge increased from $6 \mu \mathrm{m}$ in the as-received condition to $12 \mu \mathrm{m}$ after 10 cuts, and to $20 \mu \mathrm{m}$ after 30 cuts.
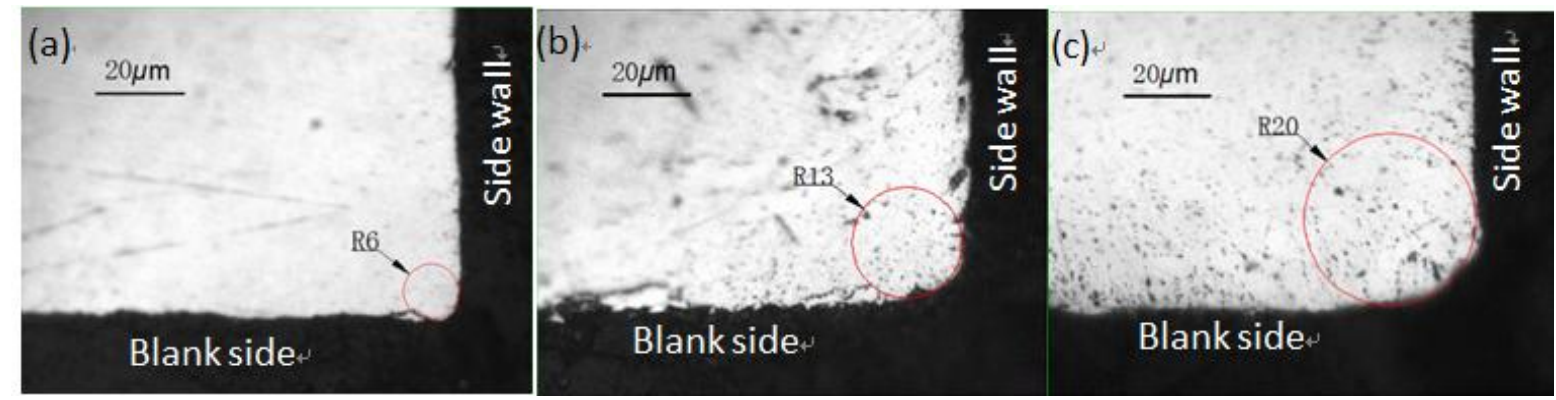

Fig. 22. Trim blade cross-sections illustrating the shape evolution of the shearing edge after: (a) 0 cuts, (b) 10

$$
\text { cuts and (c) } 30 \text { cuts }
$$

In addition to the experimental study, thirty sequential simulations of the $\mathrm{EH}$ trimming process with identical electric discharge parameters were carried out. The results are shown in the form of accumulated plastic equivalent strain in Fig. 23. In this analytical study the maximum plastic equivalent was observed to increase significantly during the first several cuts. Later, due to the work hardening of the tool, the increments of plastic deformation become smaller. In general, the shape of the EH trimming tool tends to stabilize. However, proving it quantitatively based upon the available experimental and numerical data was not possible. 


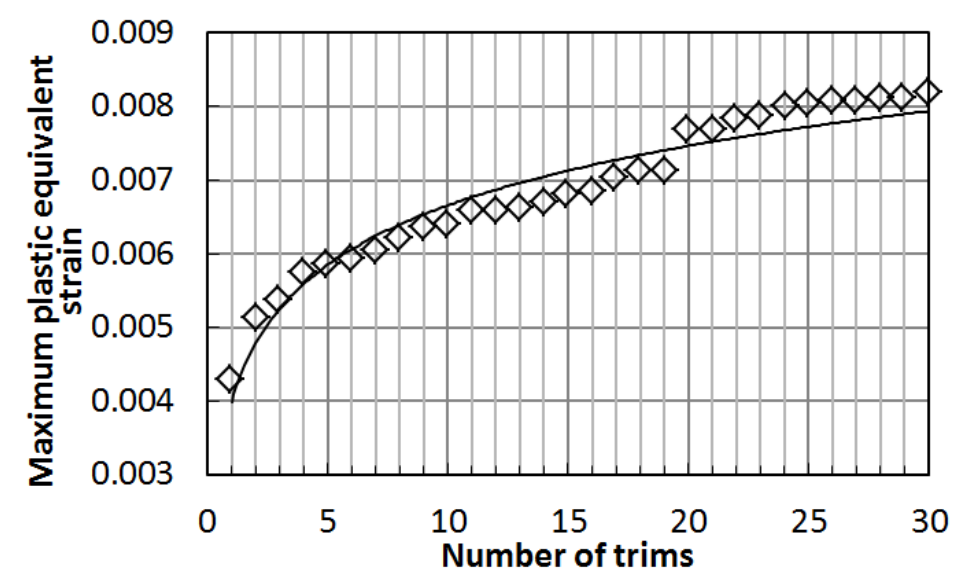

Fig. 23 Accumulated maximum plastic equivalent strain in the trim blade after each trimming event

\subsection{Comparison with conventional trimming}

In order to assess the shearing edge working conditions in EH trimming and make practical recommendations for die material selection for the $\mathrm{EH}$ trimming process, the results of numerical $\mathrm{EH}$ trimming simulations were compared with the numerical results for conventional trimming using identical tool steel and sheet metal material. The 2D numerical simulation of conventional trimming illustrated in Fig. 24 was built using the same solid element type and maintained the same cutting edge sharpness. The blank is supported by the lower trim tool and the clamping pad. The lower trim tool was fixed while the upper trim tool moves vertically down at a speed of $1 \mathrm{~m} / \mathrm{s}$. The blank is thus trimmed by the relative movement between the upper and the lower trim tools. The clearance between the shearing edges was set at 5\%, $10 \%$ and $20 \%$ of the sheet metal thickness, respectively. Other settings, such as the element type, material model, contact model and adaptive remeshing, were the identical to those in EH trimming modelling.

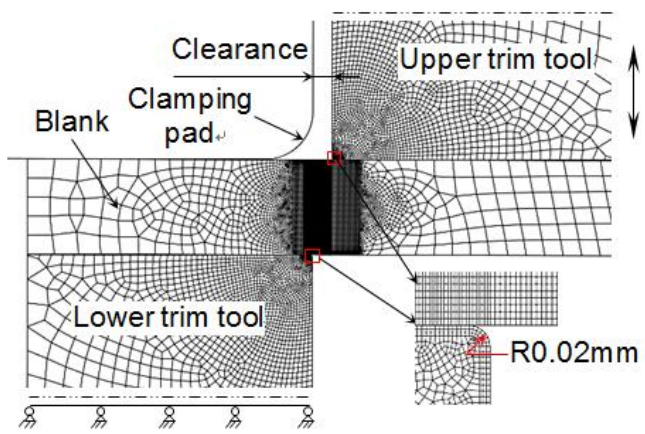

Fig. 24 2D solid element model of conventional trimming process 
The results for the upper and lower trim tools under conventional trimming are very similar to those found for the EH trimming process. Both upper and lower trim tools under conventional trimming process exhibit a volume of maximum plastic deformation just above the cutting edge radius in the trim tool side wall - although the maximum contact pressure is located instead on the horizontal surface at the other end of the cutting edge radius. Fig. 25 shows maximum contact pressures and maximum plastic equivalent strains for the trim tool when operated at different clearances. Due to the fixed boundary condition on the lower trim tool, it sees $200-300 \mathrm{MPa}$ higher contact pressures than the upper trim tool. However, the maximum plastic deformation was found to be 0.002 higher in the upper trim tool than in the lower trim tool. Die clearance had some effect on the loads observed at the shearing edges: higher contact pressures and higher plastic deformation were observed for conventional trimming when performed at higher clearances. In addition, the contact pressures found in the conventional trim tool were only about $300 \mathrm{MPa}$ less than that found in the EH trimming process by using the current process parameters. In fact, the safe contact pressure for the high speed process (EH trimming) can be higher since the flow stress of the tool in the dynamic process is higher due to increased strain rate, as seen in Fig. 6. Moreover, the plastic deformation found in the conventional trim tool is slightly higher than that found in the EH trim tool due to the longer time scale of the process. Therefore, analysis suggests the tool lives under EH trimming process present similar issues as those found under conventional trimming. One of the most significant advantages of EH trimming process is that, after re-sharpening of the shearing edge, no cutting clearance realignment is necessary.
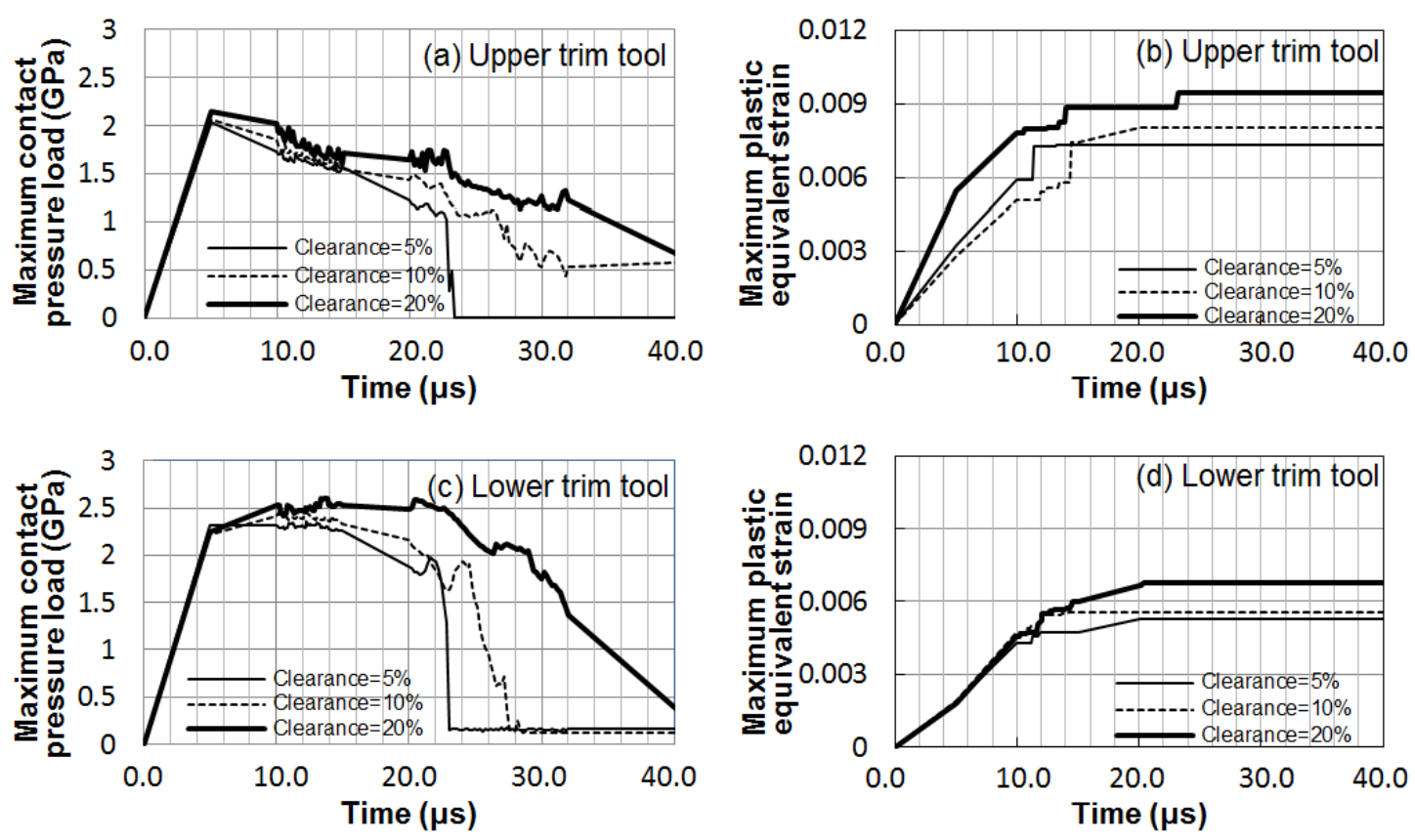

Fig. 25 Results of 2D solid element model for conventional trimming process 


\subsection{Recommendations}

The EH trimming tool analysis using D2 tool steel heat treated to HRC62 indicated that some plastic deformation of the shearing edge will occur. In order to have a more stable and reliable trimming process, the trimming tool material should not plastically deform. In order to define a tool material requirement under which the tool deformation would remain purely elastic, a further analysis using an elastic trim blade model was also conducted. Fig. 26 provides the evolution of the maximum equivalent stress through the entire EH trimming process where the peak value reaches $2.35 \mathrm{GPa}$. Thus, the material with the yield stress of $2.5 \mathrm{GPa}$ would be an appropriate choice for an EH trimming tool. Specifications of the tool steel Sleipner are provided by Uddeholm (2013). Since the maximum loads are approximately within $0.02 \mathrm{~mm}$ distance from the surface of the tool, the issue can be further addressed by increasing the strength of the surface layer of the shearing edge by using Physical Vapor Deposition applied over an Ion Nitride layer by Hall et al. (2011) or Laser Hardening by Johnson et al (2008).

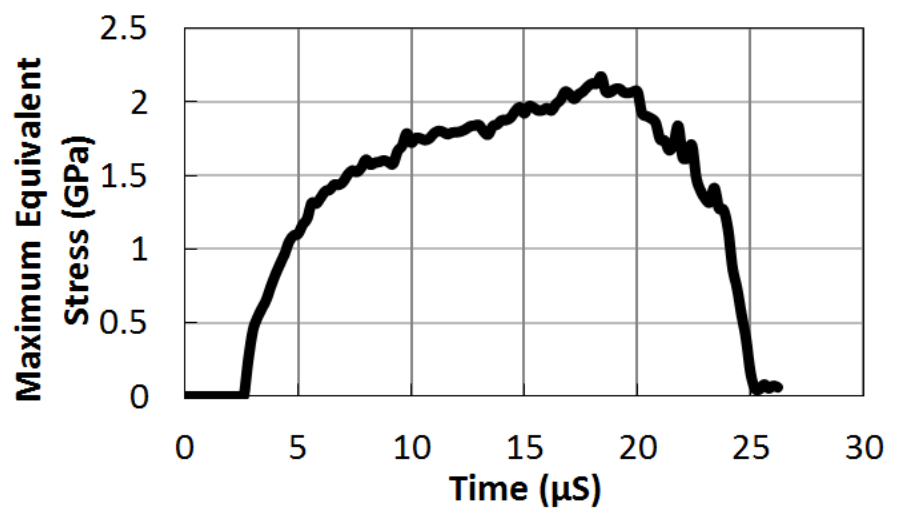

Fig. 26 Maximum equivalent stresses in the EH trim tool derived from the elastic material model simulation

\section{Conclusions}

1. An analysis of shearing edge performance for the new process of Electrohydraulic trimming has identified areas of maximum loads on the trimming tool and requirements for the shearing edge yield stress. A hybrid finite element analysis procedure combining a 3D shell simulation and 2D solid simulation was employed to simulate the EH trimming process and analyze the trim tool loads and deformations. 
2. Under EH trimming, the trim blade sees maximum contact pressures near the beginning of the cutting edge radius while plastic deformation is mostly concentrated in the area close to the surface of the trim blade's sidewall near the end of the cutting edge radius. The trim blade sees lower contact pressures and plastic deformation as shearing edge radius is increased. The trim blade cutting edge has a tendency to dull with increasing number of trimming cycles if the effective stress in the tool exceeds the yield stress.

3. In conventional trimming process, a firmly restrained trim tool has higher contact pressures but lower plastic deformation than the moving trim tool. Increasing the clearance between shearing edges under conventional trimming results in higher contact pressures and higher plastic deformation within the trim tool. Comparison of the loads applied to the trim tool under electrohydraulic trimming and in conventional trimming indicated that the contact pressure for conventional trimming is about 10-15\% lower than for Electrohydraulic trimming. However, the strength of the tool in dynamic loading in EH trimming should be higher due to the effect of increasing the flow stress at high strain rates.

\section{Acknowledgements}

This material is based upon work supported by the Advanced Manufacturing Office of the US Department of Energy under Award Number DE-FG36-08GO18128.

\section{Disclaimer}

This report is prepared as an account of work sponsored by an agency of the United States Government. Neither the United States Government nor any agency thereof, nor any of their employees, makes any warrantee, express or implied any legal liability or responsibility for the accuracy, completeness, or usefulness of any information, apparatus, product, or process disclosed, or represents that its use wouldn't infringe any privately owned rights. Reference herein to any specific commercial product, process or service by trade name, trademark, manufacturer, or otherwise does not necessarily constitute or imply its endorsement or recommendation or favouring by the United States Government or any agency thereof. The views and opinions of authors expressed herein do not necessarily state or reflect those of the United States Government or any agency thereof.

\section{References}

Becze C.E., 2002. A thermo-mechanical force model for machining hardened steel. McMaster University. Open Access Dissertations and Theses. Paper 924. 
Breitling, J., 1998. The challenges and Benefits of High Speed Blanking. Universität Stuttgart (Dr. Ing. Dissertation, ISBN 3883552666).

Bruno, E.J., 1968. High Velocity Forming of Metals. American Society of Tool and Manufacturing Engineers, Dearborn, MI, USA, pp. 73-108.

Cheah, L., Heywood, J., 2011. Meeting US passenger vehicle fuel economy standards in 2016 and beyond. Energy Policy. 39, 454-466.

Chen, G., 2011. Modeling of Fracture in AHSS Component Crush Tests. Great Designs in Steel Seminar, available online at www.autosteel.org.

Chintamani, J., Sriram S., 2006. Sheared Edge Characterization of Steel Products used for Closure Panel Applications. SAE Paper 2006-01-1589.

Daehn G.S, 2006. High Velocity Metal Forming. Metalworking: Sheet metal Forming, vol. 14B. ASM Handbook, pp.405-418.

Das, M.K., Sadollah, Z.T., 1979. Cropping billets with low aspect ratios. In: Proceedings of 20th International Machine Tool and Design Conference, Birmingham, pp.195-202.

Davies, G., 2003. Materials for Automotive Bodies, Elsevier, pp.277.

Gafri, O., Livshiz, Y., 2004. Electromagnetic and/or electrohydraulic forming of a metal plate. US patent $6,708,542$

Golovashchenko, S.F., 1995. Electromagnetic impulse joining and shearing of Al-Cu and Al-Mg alloy tubes. Aluminum and Magnesium for Automotive Applications. In: Proceedings of Fall TMS Meeting, Cleveland, pp. 209-221. 
Golovashchenko, S.F., 2010. Electrohydraulic trimming, flanging, and hemming of blanks. US Patent 7,810,366.

Golovashchenko, S.F., Gillard, A.J., Mamutov, A.V., Bonnen, J.J.F., Tang, Z., 2014. Electrohydraulic Trimming of Advanced and Ultra High Strength Steels. Journal of Materials Processing Technology. 214, 1027-1043.

Hall, J., Mulholland, T., Young, D., McGuire, J.P., 2011. Investigation of Stamping Tooling Durability for Dual Phase Steels. SAE Paper 2011-01-1060.

Johnson, G.R., Cook, W.H., 1983. A constitutive model and data for metals subjected to large strains, high strain rates and high temperatures. Proceedings of the 7th International Symposium on Ballistics. pp. 541-547.

Johnson, P., Kjellsson, K., Stenberg, N., Wiklund, D., 2008. Laser hardened trimming tools: wear test and geometry evaluation. In: Proceedings of the IDDRG 2008 Conference "Best in class stamping", Olofström, Sweden, p.639-650.

Johnson, W., Slater, R.A.C., 1966. Further experiments on quasi-static and dynamic blanking of circular discs from various materials. Proceedings of the Institution of Mechanical Engineers. 180 (3I), 163-181.

Kautz, T., 2008. Impulsmagnetisches Beschneiden von dünnwandigen Hohlprofilen. Otto-von-GuerickeUniversität Magdeburg (Dr. Ing. Dissertation, ISBN 9783832269159).

Klepaczko, J.R., Klosak, M., 1999. Numerical study of the critical impact velocity in shear. European Journal of Mechanics A/Solids. 13, 93-113.

Li, M., 2000. An experimental investigation on cut surface and burr in trimming aluminum autobody sheet. International Journal of Mechanical Sciences. 42, 889-906.

Maeda, T., Matsuno, K., 1967. Wear on Shearing Tools. Bulletin of JSME. 10(37), 197-205. 
Mynors, D.J., Zhang, B., 2002. Applications and capabilities of explosive forming. Journal of Materials Processing Technology. 125-126, 1-25.

Nakagawa, T., Shimori, K., 1974. Production of Crank $\neg$ shafts by Clamp Shearing. In: Proceedings of the 15 th Internatonal Machine Tool Design and Research Conference, London, pp.611-616.

Psyk, V., Risch, D., Kinsey, B.L., Tekkaya, A.E., Kleiner, M., 2011. Electromagnetic forming - A review. Journal of Materials Processing Technology. 211, 787-829.

Singh, H, 2003. Fundamentals of Hydroforming. Society of Manufacturing Engineers, Dearborn, pp.29-35.

Smith, D., 1990. Die design handbook. Society of Manufacturing Engineers, Dearborn, MI.

Taber, G.A., Kabert, B.A., Washburn, A.T., Windholtz, T.N., Slone, C.E., Boos, K.N., Daehn, G.S., 2012. An Electromagnetically Driven Metalworking Press. In: Proceedings of 5th International Conference on High Speed Forming, Dortmund, Germany, 125-134.

Thompson, A.C., 2006. High Strain Rate Characterization of Advanced High Strength Steels. University of Waterloo (Master's Degree Thesis).

Udeholm, 2013. Sleipner cold work tool steel. http://www.uddeholm.com.br/br/files/Sleipner_english_04.pdf. Downloaded on November $26^{\text {th }} .2013$

Uhlmann, E., Scholz, M., 2003. Zerteilen von Aluminiumblechen durch Impulsmagnetfelder. Tagungsband zum 2. Kolloquium Elektromagnetische Umformung, Dortmund, Deutschland, pp. 87-94. 
Fig. 24 2D solid element model of conventional trimming process

Fig. 25 Results of 2D solid element model for conventional trimming process

Fig. 26 Maximum equivalent stress of the EH trim tool derived from the elastic material model simulation 